\title{
JOURNAL
}

of Health Inequalities

\section{Towards improved public health: Affecting alcohol and tobacco affordability and consumption in Poland through taxation}

\author{
Michał Stokłosa', Jeffrey Drope ${ }^{1,2}$, Mateusz Zatoński ${ }^{3,4}$, Witold A. Zatoński ${ }^{3,5}$ \\ 'American Cancer Society, Atlanta, GA, USA \\ ${ }^{2}$ Department of Political Science, Marquette University, Milwaukee, WI, USA \\ ${ }^{3}$ Health Promotion Foundation, Nadarzyn, Poland \\ ${ }^{4}$ London School of Hygiene and Tropical Medicine, London, UK \\ ${ }^{5}$ Higher Vocational State School in Kalisz, Poland
}

\begin{abstract}
Alcohol consumption levels, as well as mortality and morbidity resulting from alcohol misuse, are at unprecedented levels in Poland. One of the most prominent factors very likely influencing this surge is the generally affordable prices of alcohol products. In 2015, Polish consumers could buy roughly twice as much beer, wine, and spirits with their disposable income compared to 2001. This increase in alcohol products affordability was one of the most pronounced among all high-income countries. One way to reverse these trends in affordability is through alcohol taxation. Cigarette taxes can serve as an example of a successful use of fiscal policy to reduce product affordability and advance public health goals. Significant cigarette tax increase resulted in higher cigarette prices and lower cigarette affordability. In Poland, from 2007 to 2015, significant declines in smoking rates and decreases in lung cancer rates were noted. Positive experiences with tobacco taxation should serve as guiding examples for governments to successfully utilise similar excise tax policy approaches in the control of alcohol-related diseases.
\end{abstract}

KEY WORDS: alcohol, tobacco, affordability, taxation.

\section{KEY FINDINGS}

1. Alcohol products in Poland are twice more affordable now than in 2001

2. Following the increase in alcohol affordability, alcohol use increased significantly and is now at the highest level in history.

3. A public policy to increase alcohol taxes can reverse these trends in alcohol affordability and therefore consumption.

4. Experiences with tobacco taxation serve as rich examples that governments can successfully utilise an excise tax policy approach to reduce product affordability and advance public health goals.

ADDRESS FOR CORRESPONDENCE: Michał Stokłosa, American Cancer Society, Atlanta, GA, USA, 250 Williams Street, 30303 Atlanta, United States, e-mail: michal.stoklosa@cancer.org

Average adult alcohol consumption in Poland is at the highest level in history. In 2015, the average adult Pole (15 years or older) drank over 11 liters of pure alcohol [1], matching the previous record set in 1980 [2]. The majority of alcohol was consumed in the form of beer (58\%), followed by spirits (34\%), and wines (8\%) [3]. Alcohol is a major risk factor to many preventable non-communicable diseases, including neuropsychiatric conditions, gastrointestinal diseases, cancers, and cardiovascular diseases, as well as to injuries, for example suicide, violence, and car crashes [4]. In Poland, the scale of the alcohol epidemic is reaching unprecedented levels [5], with alcohol 


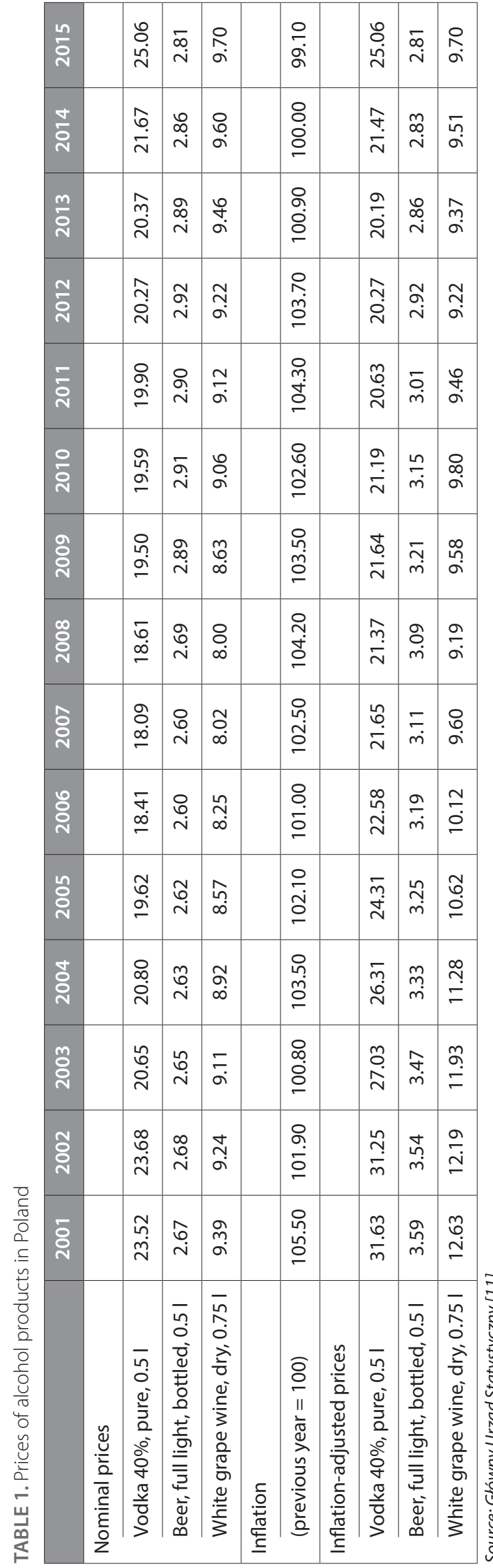

misuse being associated with an estimated 17,000 deaths in 2015 [6]. In addition, Poland belongs to a group of European countries, in which a large proportion of alcohol is consumed during occasional heavy sessions of drinking, i.e. through so-called 'binge drinking', which is associated with particularly high levels of injury and sudden death mortality [7]. Moreover, significant gender and socio-economic differentials exist in both consumption levels and morbidity/mortality rates in Poland [8]. While on average, men drink four to five times more alcohol than women in Poland, higher education and urban residency area are associated with less alcohol consumed for men, but more alcohol consumed for women [8].

Among many factors that influenced this surge of alcohol misuse in Poland, including socio-demographic determinants [2], alcohol product marketing and accessibility [4], perhaps the most important determinant, has been available at affordable prices. A large body of literature has found rising alcohol price to be strongly associated with reduced alcohol consumption $[9,10]$. In case of alcohol prices increase, many consumers decide to reduce their alcohol consumption or to stop purchasing alcohol altogether. On the contrary, declining alcohol prices encourage consumption. Between 2001 and 2015 , inflation-adjusted prices of alcohol products have fallen across all product categories in Poland. Prices have been steadily falling for beer and leveled off around 2005 for wine. Spirit prices slightly increased in 2014 and 2015 but these products on average still cost well below what they previously did in the early 2000's (Table 1).

While the price is likely to be the single largest determinant of demand, another economic factor, specifically disposable income, also plays a crucial role in shaping alcohol use behaviors. Alcohol products are found to have a positive income elasticity of demand: people tend to buy more alcohol when their incomes increase [10]. Between 2001 and 2015, the average disposable income in Poland increased by $62 \%$ in inflation-adjusted terms [11]. With the rapid growth in their purchasing power, people discovered that many products, including alcohol, had become more affordable.

Because consumers' purchasing behaviors are influenced by product price and their own disposable income, economists use the ratio of these two factors to determine product affordability. Such a ratio can be interpreted as the percentage of income that is needed to buy the product. The greater the proportion of income required to purchase alcohol products, the less affordable these products are. Figure 1 presents the index of affordability of alcohol products from 2001 to 2015. In this Figure, the affordability of all products in 2001 are set to one. As the Figure illustrates, all categories of alcohol products became significantly more affordable over time due to decrease in alcohol prices and increase in income. In 2015 , consumers could buy roughly twice as much beer, wine, and spirits with their disposable income compared 


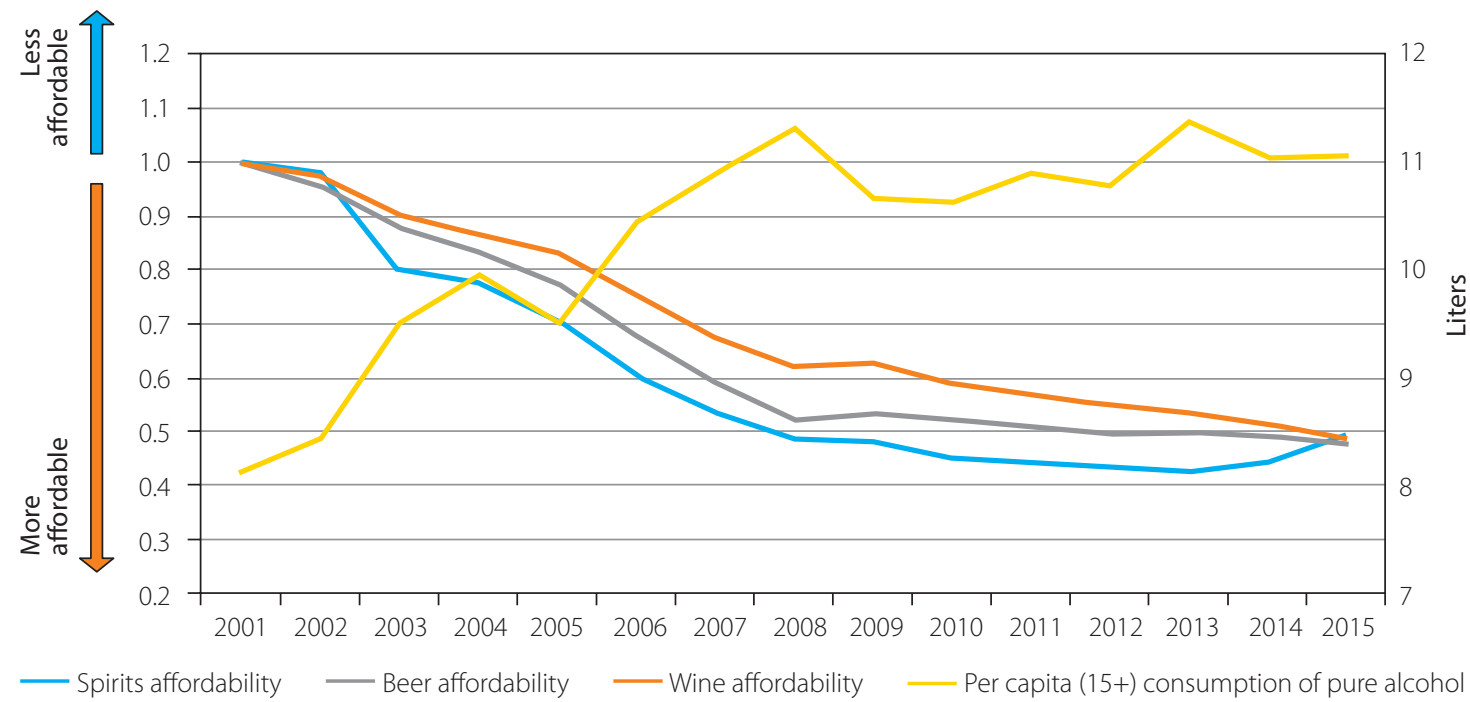

FIG. 1. Affordability index for alcohol products $(2001=1)$ vs. alcohol consumption in Poland. Source: Główny Urząd Statystyczny [11]

to 2001. According to a recent international analysis of alcohol affordability, the increase in alcohol product affordability observed in Poland is one of the most rapid among all high-income countries [12].

One way to reverse these trends of increased alcohol product affordability is to raise excise taxes on alcohol products. Once the government will increase excise taxes sufficiently, alcohol products producers and sellers' need to increase their prices in order to stay profitable. Cigarette taxes can serve as an example of such a successful use of fiscal policy to reduce product affordability and advance public health goals. In recent years, due to Poland's obligations to European Union (EU) membership, tobacco excise taxes in Poland needed to be increased in order to meet the EU minimums [13]. Consequently, the specific excise tax increased from 50,00 PLN per 1,000 cigarettes in 2001 to 206.76 PLN per 1,000 cigarettes in 2015. At the same time, the ad valorem tax increased from $25.00 \%$ to $31.41 \%$ of the retail sales price. These tax increases resulted in higher cigarette prices. For example, the inflationadjusted price of a pack of a Marlboro cigarettes increased by $66 \%$ from 8,74 PLN in 2001 to 14,5 PLN in 2015 [14]. After 2007, cigarette prices increased faster than people's disposable incomes, cigarettes became less affordable over time (Fig. 2). These tax and price increases were associated with significant declines in smoking rates in Poland [15], and were followed by a decrease in lung cancer morbidity and mortality, especially in the male population [16].

Tax policy for alcohol products has been very different than for cigarettes. From January to August 2001, tax rates for beer and wine increased by $19 \%$, while tax rates for spirits increased by $4 \%$. These tax increases were followed by declines in consumption across all alcohol product categories [3]. In August 2002, however, the Minister

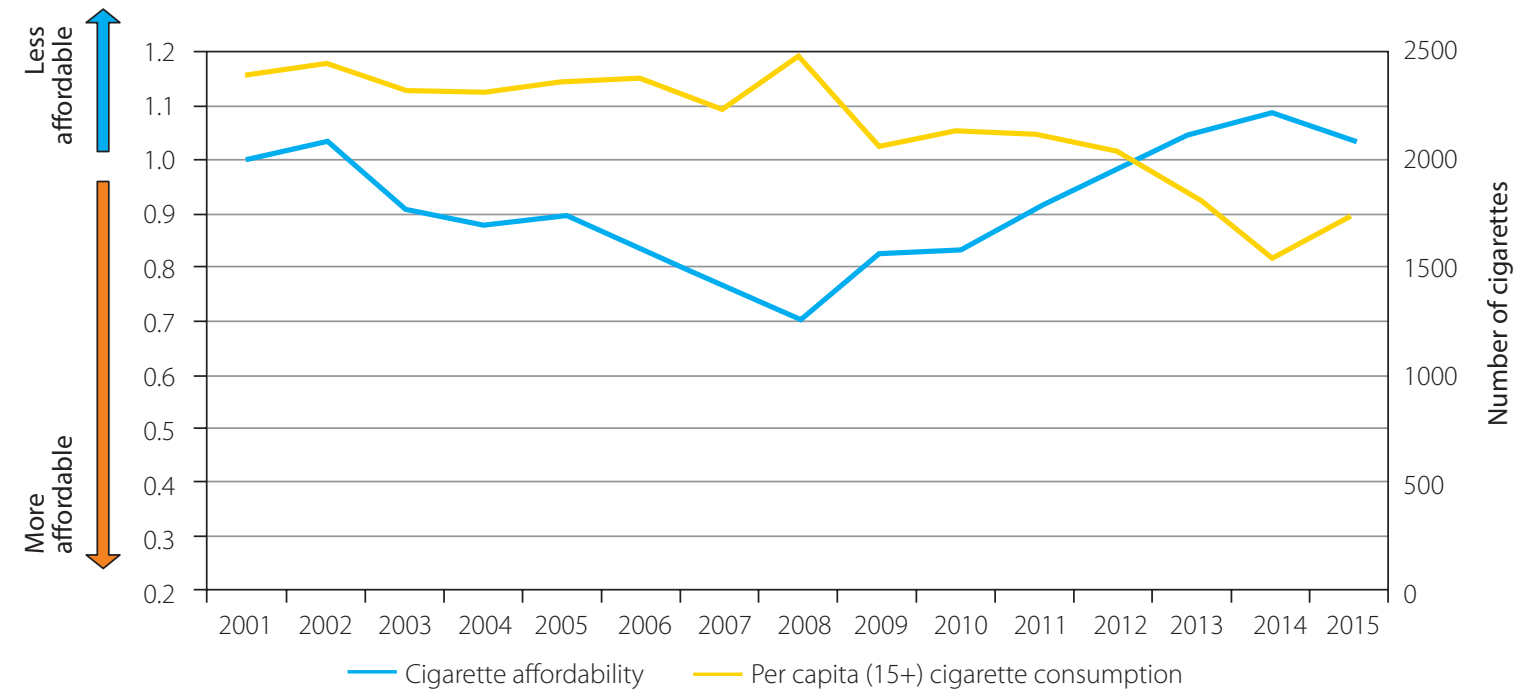

FIG. 2. Affordability index for cigarettes $(2001=1)$ vs. cigarette consumption in Poland. Source: Główny Urząd Statystyczny [11], Economist Intelligence Unit [14] 
of Finance decreased the excise tax on spirits by $30 \%$, from 6,278 PLN to 4,400 PLN per hectoliter of pure alcohol. The decline in spirit taxes was immediately followed by a sharp increase in spirit consumption, which resulted in a decline in health gains in Poland in the subsequent years [17]. After tax decrease, spirits became more affordable more quickly than other alcohol products (Fig. 1). From 2003 to 2015, the government increased excise taxes on beer and wine only once, while spirit taxes increased three times (2005, 2009, and 2014). Nevertheless, these beer, wine, and spirit tax increases were minor and did not keep up with inflation. Notably, even these small increases were met with fierce opposition by the alcohol lobby, whose arguments dominated the public and media debate [18].

The World Health Organization (WHO) identifies increased taxation as one of the "best buys" in reducing alcohol-related harms by negatively affecting the demand for alcoholic beverages [4]. The WHO's Global Strategy to Reduce the Harmful Use of Alcohol recommends that countries regularly review alcohol product prices in relation to levels of inflation and income [19]. To make alcohol products less affordable over time, alcohol excise tax increases need to be significant enough, so that the growth in alcohol prices outpaces the growth in consumers' disposable income. Moreover, alcohol excise tax increases should be even more effective in decreasing the demand for these products, and in reducing harm related to the product use than cigarette taxes, because demand for alcohol products, especially for wine and spirits, tends to be more sensitive to price changes $[9,10]$ than the demand for cigarettes [20]. Moreover, as people from lower socio-economic groups are usually more responsive to price changes than others, alcohol taxes should be most effective among the heaviest drinkers in Poland, which are rural, poorly-educated men. Positive experiences with tobacco taxation should serve as guiding examples for governments to successfully utilise similar excise tax policy approaches in the control of alcohol-related diseases.

\section{DISCLOSURE}

Authors report no conflict of interest.

\section{References}

1. World Health Organization. World Health Statistics 2016. Geneva 2016.

2. Swiątkiewicz G, Wieczorek L, Allamani A. What influences changes in alcoholic beverage consumption over time? Poland in the light of the European Union Amphora study. Subst Use Misuse 2014; 49: 1601-1610.

3. Państwowa Agencja Rozwiązywania Problemów Alkoholowych (PARPA). Statystyki [The State Agency for Prevention of Alcohol-related Problems. Statistics]. Warsaw, Poland 2016. Available from: http://www.parpa.pl/index.php/badania-i-informacje-statystyczne/statystyki (accessed 18 November 2016).

4. World Health Organization. Global status report on alcohol and health. Geneva, World Health Organization 2014. Available from: http://www.who.int/substance_abuse/publications/global_alcohol_ report/msb_gsr_2014_1.pdf?ua=1 (accessed 19 November 2016).

5. Rehm J, Zatonksi W, Taylor B, et al. Epidemiology and alcohol policy in Europe. Addiction 2011; 106 Suppl. 1: 11-19.

6. Institute for Health Metrics and Evaluation (IHME). GBD Compare Data Visualization. Seattle, WA: IHME, University of Washington 2016. Available from: http://vizhub.healthdata. org/gbd-compare (accessed 18 November 2016).

7. Rehm J, Sulkowska U, Mańczuk M, et al. Alcohol accounts for a high proportion of premature mortality in central and eastern Europe. Int J Epidemiol 2007; 36: 458-467.

8. Wojtyniak B, Moskalewicz J, Stokwiszewski J, et al. Gender-specific mortality associated with alcohol consumption in Poland in transition. Addiction 2005; 100: 1779-1789.

9. Wagenaar AC, Salois MJ, Komro KA. Effects of beverage alcohol price and tax levels on drinking: a meta-analysis of 1003 estimates from 112 studies. Addiction 2009; 104: 179-190.

10. Gallet CA. The demand for alcohol: a meta-analysis of elasticities. Aust J Agric Resour Econ 2007; 51: 121-135.

11. Główny Urząd Statystyczny. Bank Danych Lokalnych [Central Statistical Office of Poland. Local databank]. Warsaw, Poland: Główny Urząd Statystyczny 2016. Available from: https://bdl. stat.gov.pl/BDL/start (accessed 19 November 2016).

12. Van WalbeekC,BlecherE. The Economics of alcohol use, misuse and policy in South Africa. South Africa: 2014. Available from: http:// tobaccoecon.org/wp-content/uploads/2014/03/the-economics-ofalcohol-policy-in-south-africa.pdf (accessed 19 November 2016).

13. Blecher E, Ross H, Stoklosa M. Lessons learned from cigarette tax harmonisation in the European Union. Tob Control 2014; 23 : e12-14.

14. Economist Intelligence Unit. World Cost of Living Survey. Economist Intelligence Unit, London 2016.

15. Ross H, Kostova D, Stoklosa M, et al. The Impact of Cigarette Excise Taxes on Smoking Cessation Rates From 1994 to 2010 in Poland, Russia, and Ukraine. Nicotine Tob Res 2014; 16: S37-43.

16. Zatoński M, Zatoński WA, Przewoźniak K, et al. The significance and impact of the Polish Anti-Tobacco Law. J Health Inequal 2016; 2: 32-35.

17. Zatoński WA, Sulkowska U, Zatoński MZ, et al. Alcohol taxation and premature mortality in Europe. Lancet 2015; 385: 1181.

18. Zatoński M, Hawkins B, McKee M. Framing the policy debate over spirits excise tax in Poland. Health Promot Int 2016; doi: 10.1093/heapro/daw093.

19. World Health Organization. Global strategy to reduce the harmful use of alcohol. Geneva, Switzerland: World Health Organization 2010. Available from: http://www.who.int/substance_ abuse/msbalcstragegy.pdf (accessed 19 November 2016).

20. IARC. IARC Handbooks of Cancer Prevention, Tobacco Control, Vol. 14: Effectiveness of Tax and Price Policies for Tobacco Control. International Agency for Research on Cancer, Lyon 2011.

\section{AUTHORS' CONTRIBUTIONS}

MS and WAZ prepared the research concept and design. MS performed the data collection and assembly. MS, JD, MZ and WAZ participated in data analysis and interpretation, in the writing of the article, in its critical revision and final approval. 